\title{
Designing cantilever dimension for low power wireless applications
}

\author{
Md Rabiul Awal ${ }^{1}$, Muzammil Jusoh ${ }^{2}$, R. Badlishah Ahmad ${ }^{3}$, Thennarasan Sabapathy ${ }^{4}$, \\ M. Najib M. Yasin ${ }^{5}$, Mohd Hafizuddin Mat ${ }^{6}$ \\ ${ }^{1}$ School of Ocean Engineering, Universiti Malaysia Terengganu (UMT), Malaysia \\ ${ }^{2,4,5}$ School of Computer and Communication Engineering, Universiti Malaysia Perlis (UniMAP), Malaysia \\ ${ }^{3}$ Faculty of Informatics and Computing, Universiti Sultan Zainal Abidin (UniSZA), Malaysia \\ ${ }^{6}$ School of Electrical Systems Engineering, Universiti Malaysia Perlis (UniMAP), Malaysia
}

\begin{tabular}{l} 
Article Info \\
\hline Article history: \\
Received Sep 20, 2018 \\
Revised Dec 22, 2018 \\
Accepted Jan 11, 2019 \\
\hline Keywords: \\
Acoustic energy \\
Acoustic signal \\
Cantilever displacements \\
Low power applications
\end{tabular}

Low power applications

\begin{abstract}
This paper presents the effect of cantilever width on the displacement pattern for low power acoustic energy propagation. A single layer cantilever configuration is used to design the harvester with Lead Zirconate Titanate (PZT-5H). The device is designed with $10 \times(1$ to 10$) \times 0.62 \mathrm{~mm}$ dimension. The displacements of the cantilever are obtained through the simulation analysis. The maximum displacements are found of $9.80 \mathrm{E}-28 \mathrm{~mm}$ with the smallest width while minimum displacement is found from $5 \mathrm{~mm}$ width. From the results, it is obvious that, smaller width can result larger displacements, however, rectangular and square cantilever shape can be advantageous for low power applications.
\end{abstract}

Copyright (C) 2019 Institute of Advanced Engineering and Science. All rights reserved.

\section{Corresponding Author:}

Muzammil Jusoh,

School of Computer and Communication Engineering,

Universiti Malaysia Perlis (UniMAP),

Kampus Pauh Putra, 02600, Arau, Perlis, Malaysia.

Email: muzammil@unimap.edu.my

\section{INTRODUCTION}

The Microelectromechanical sensors (MEMS) have wide range of applications due to their flexible characteristics [1,2]. Their physical geometry is highly advantageous for the applications in micrometer level, however, the geometry pattern can be applied to even meter range structural applications [3, 4]. In fact, numerous example of these pattern similarity can be found even in construction models and can be several hundred meters in length. Hybrid energy harvesting platform can also be integraded with these MEMS [5].

Among micrometer to millimeter range MEMS, cantilever pattern is one of the mostly applied device patterns. Their main applications lied within acoustic signal transmitter and receiver, imaging in atomic force microscopy (AFM) [6]. In recent proposal, cantilever also used for acoustic energy transfer (AET) [7]. For all the cases of applications, the high sensitivity of the device is the key feature [8]. Though, cantilever has significant applications in the low power AET, however, the proper geometry dimension is unavailable for this particular area of interest $[9,10]$.

From these motivations, in this paper, we investigate the cantilever dimension considering various length, width and thickness. We intend to observe the impact of the different dimensions on the device displacements [11]. Due to the application focus, we limit our investigation to the rectangular shape only. The maximum dimension is considered as, $10 \mathrm{~mm}$ in length, $10 \mathrm{~mm}$ in width and $0.625 \mathrm{~mm}$ in thickness. In addition, we have applied a range of voltage to trace the effect in device behavior according to the existing 
literarture $[12,13]$. In this work, we have considered the rectangular shaped pattern only and extended the observations to the square patterned device.

The reminder of this paper is organized as follows; Section 2 presents the governing equations of the device displacements. Sections 3 describes the design parameters of the cantilever in detail. Section 4 discusses the displacement pattern of the cantilever. Lastly, Section 5 concludes this paper with some prospective future agendas.

\section{GOVERNING EQUATIONS FOR THE DEVICE DISPLACEMENTS}

A cantilever beam with an applied uniform load exhibits the maximum stress as [14],

$$
\sigma=\frac{P L}{Z}
$$

And maximum deflection as [15],

$$
\mathrm{D}=\frac{\mathrm{PL}^{3}}{3 \mathrm{EI}}
$$

Where,

$\mathrm{P}=$ force,

$\mathrm{L}=$ length of the beam,

$\mathrm{Z}=$ section modulus,

$\mathrm{E}=$ flexural modulus,

$\mathrm{I}=$ moment of inertia about bending axis.

For a rectangular shaped cantilever, $\mathrm{Z}$ and I can be defined as [16],

$$
Z=\frac{b t^{2}}{6}
$$

And,

$$
I=\frac{b t^{2}}{12}
$$

Here, $b$ and $t$ are the width and thickness of the cantilever respectively.

It is important to notice that, larger width and thickness compared to the device length, results larger values for the section and flexural modulus and moment of inertia. These values limit the maximum stress and deflection of the device in terms of displacements. Though, higher delivered force can offer higher deformation, however, exceeding the threshold value also may introduce permanent deformations. Hence, the ratio of the length to width and thickness is important to consider in designing.

\section{DEVICE DESCRIPTIONS AND MODELING}

The device geometry is settled according to the length, width and thickness. However, device length and thickness is considered as unchanged while we have set width values from $1 \mathrm{~mm}$ to $10 \mathrm{~mm}$. Thus, varies the device volume as well. The detail descriptions are given in Figure 1 and the following Table 1. Displacements vs. applied voltages as shown in Figure 2.

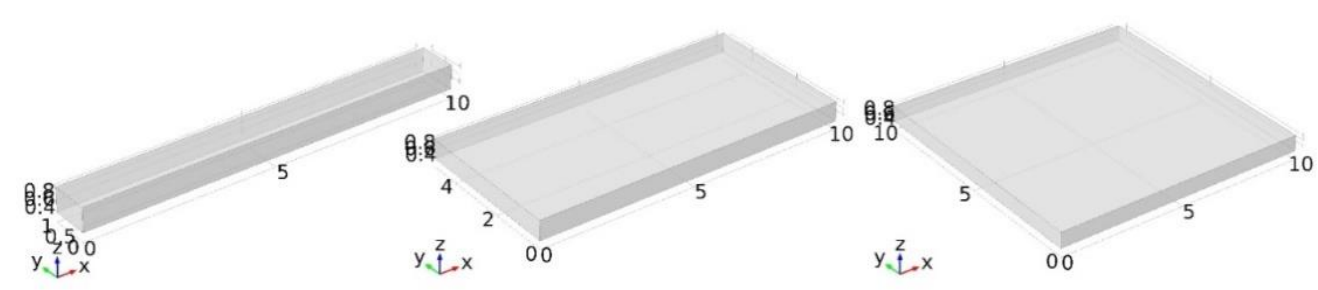

Figure 1. Cantilever design descriptions 


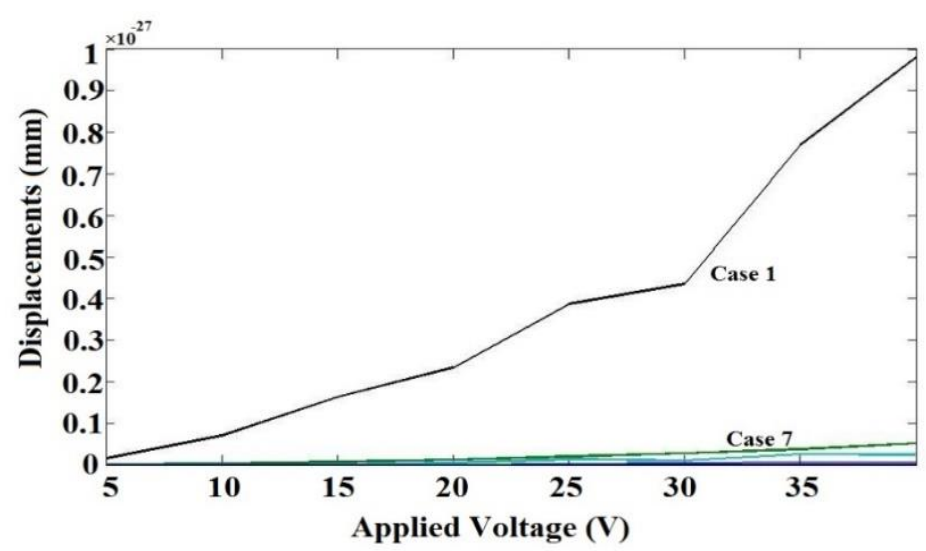

Figure 2. Displacements vs applied voltages

Table 1. Cantilever Dimension Descriptions

\begin{tabular}{ccc}
\hline Case & $\begin{array}{c}\text { Cantilever Dimensions }(\mathrm{mm}) \\
\text { Length } \times \text { Width } \times \text { Thickness }\end{array}$ & Device Volume $\left(\mathrm{mm}^{3}\right)$ \\
\hline 1 & $10 \times 1 \times 0.62$ & 6.2 \\
2 & $10 \times 2 \times 0.62$ & 12.4 \\
3 & $10 \times 3 \times 0.62$ & 18.6 \\
4 & $10 \times 4 \times 0.62$ & 24.8 \\
5 & $10 \times 5 \times 0.62$ & 31 \\
6 & $10 \times 6 \times 0.62$ & 37.2 \\
7 & $10 \times 7 \times 0.62$ & 43.4 \\
8 & $10 \times 8 \times 0.62$ & 49.6 \\
9 & $10 \times 9 \times 0.62$ & 55.8 \\
10 & $10 \times 9 \times 0.62$ & 62 \\
\hline
\end{tabular}

\section{DISPLACEMENTS OF THE CANTILEVER}

Displacements of the device are achieved by the simulation modeling. As mentioned earlier, device length and thickness are fixed but the width is varied from $1 \mathrm{~mm}$ to $10 \mathrm{~mm}$. Lead Zirconate Titanate $(\mathrm{PZT}-5 \mathrm{H})$ is selected as the device material. After designing the device, a list of voltages is applied. The voltages ranged from $5 \mathrm{~V}$ to $40 \mathrm{~V}$ with $5 \mathrm{~V}$ increment, i.e. $5 \mathrm{~V}, 10 \mathrm{~V}, 15 \mathrm{~V}$ to $40 \mathrm{~V}$ sequentially.

These applied voltages create piezoelectric effect eventually and the effect can be found in displacement form. Ideally, higher voltage should result larger displacements. However, in several cases, lower voltage introduces higher displacement (case 3, 6 and 10). Reasonably, this incident depends on the operating resonant frequency of the cantilever.

Maximum displacement is found in case 1 with the device dimension of $10 \times 1 \times 0.62 \mathrm{~mm}$. The measured displacement is $9.80 \mathrm{E}-28 \mathrm{~mm}$ when $40 \mathrm{~V}$ is applied. Case 7 and 10 exhibit the next higher displacements with $7.79 \mathrm{E}-32 \mathrm{~mm}$ and $2.55 \mathrm{E}-29 \mathrm{~mm}$ values when $35 \mathrm{~V}$ is applied for both cases. Interestingly, case 10 designs a square cantilever where case 7 has the rectangular shape. Among others, case 5 has the higher displacement as $7.85 \mathrm{E}-30 \mathrm{~mm}$ with $40 \mathrm{~V}$ applied voltage.

From the results in Table 2 and Figure 2 and Figure 3, we can observe some obvious conclusions. In the context of displacement, case 1 is the dominating device pattern. However, for acoustic propagation pattern and signal power level, case 7 and 10 are better choices due to their device size.

In addition, nonuniform stress distributions are also found in some cases (case 4, 5, 7 and 8). These nonuniform stress distributions have inverse effect on the device behavior. Specifically, when found on the device tip, it can exhibit nonlinear, even reverse displacement patterns. This leads to the uncontrolled acoustic propagation and direction. In progression, it may introduce to the device failure or breakdown. Maximum displacements of the cantilever for different cases (6 - 10) as shown in Figure 4. 
Table 2. Maximum Cantilever Displacements

\begin{tabular}{ccc}
\hline Case & $\begin{array}{c}\text { Cantilever Dimensions }(\mathrm{mm}) \\
\text { Length } \times \text { Width } \times \text { Thickness }\end{array}$ & $\begin{array}{c}\text { Device } \\
\text { Volume }\left(\mathrm{mm}^{3}\right)\end{array}$ \\
\hline 1 & $9.80 \mathrm{E}-28$ & 40 \\
2 & $2.27 \mathrm{E}-33$ & 40 \\
3 & $2.43 \mathrm{E}-30$ & 30 \\
4 & $2.78 \mathrm{E}-34$ & 40 \\
5 & $7.85 \mathrm{E}-30$ & 40 \\
6 & $7.79 \mathrm{E}-32$ & 35 \\
7 & $5.15 \mathrm{E}-29$ & 40 \\
8 & $3.59 \mathrm{E}-35$ & 40 \\
9 & $3.21 \mathrm{E}-30$ & 40 \\
10 & $2.55 \mathrm{E}-29$ & 35 \\
\hline
\end{tabular}
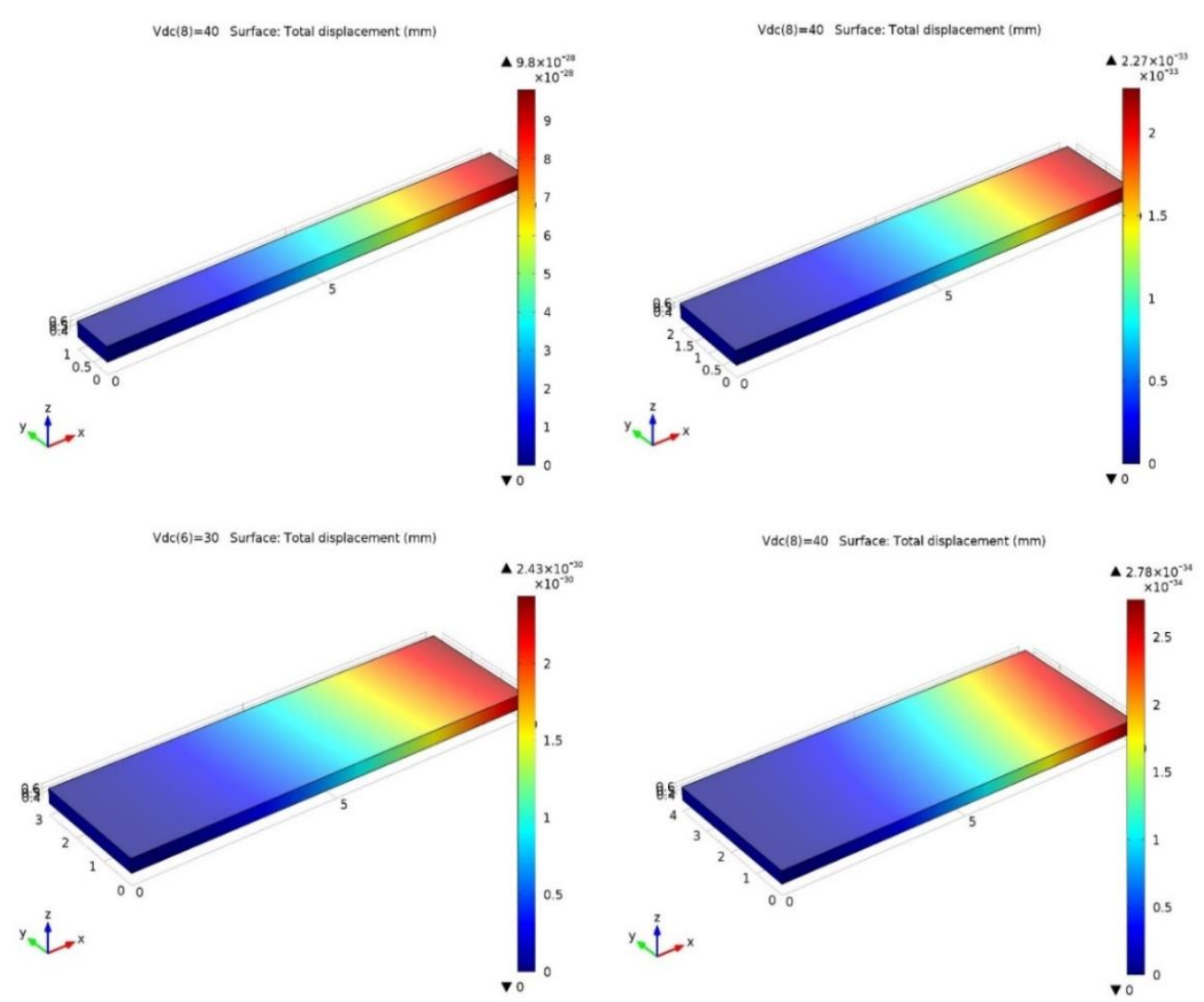

$V d c(8)=40$ Surface: Total displacement $(\mathrm{mm})$

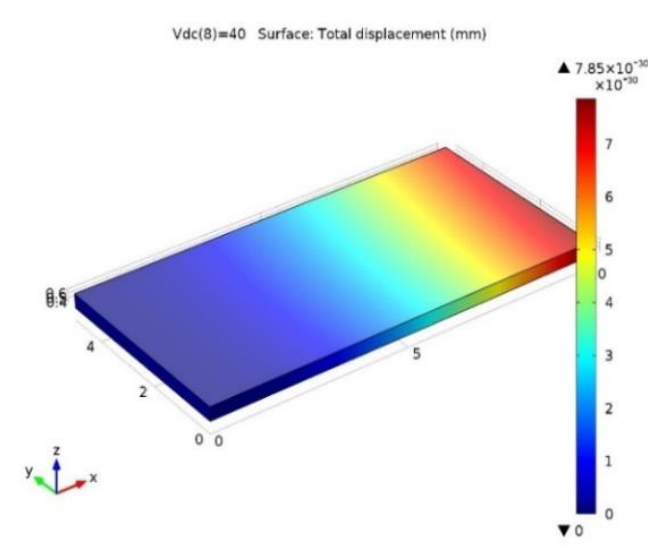

Figure 3. Maximum displacements of the cantilever for different cases (1 - 5) 

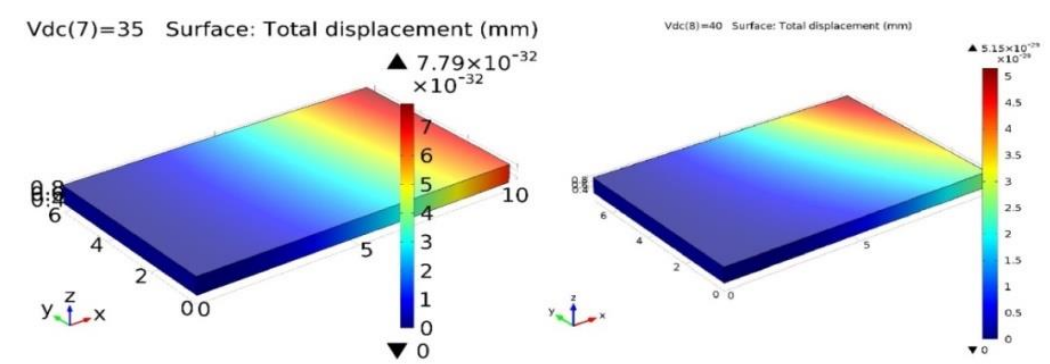

$\operatorname{Vdc}(8)=40$ Surface: Total displacement $(\mathrm{mm})$

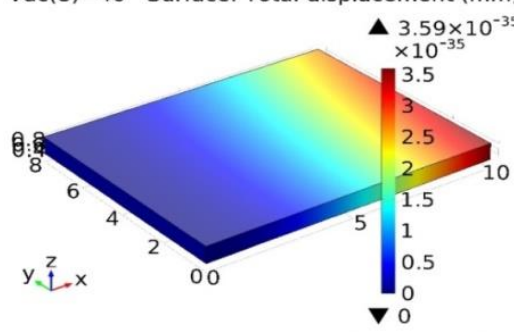

$\operatorname{Vdc}(8)=40 \quad$ Surface: Total displacement $(\mathrm{mm})$
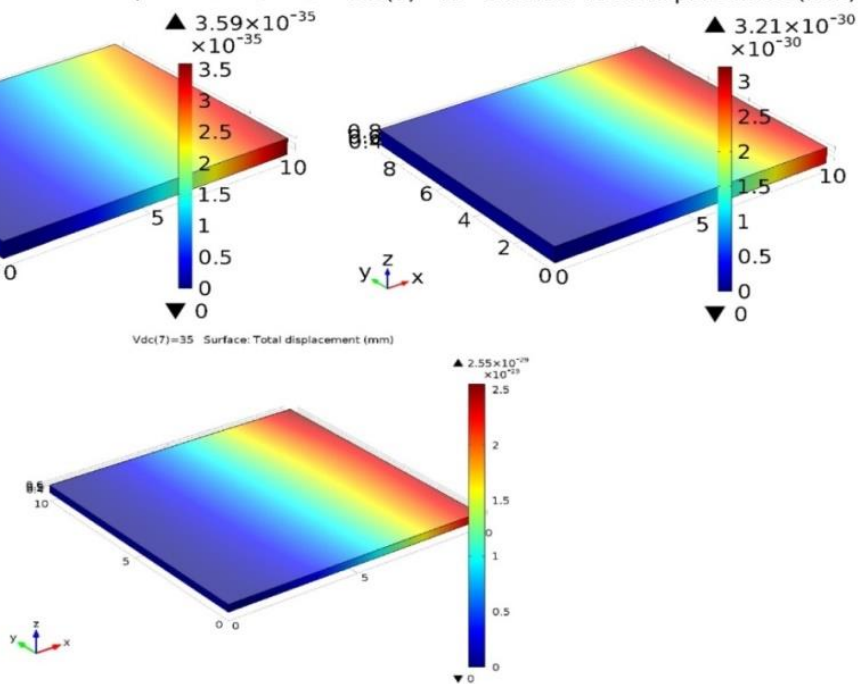

Figure 4. Maximum displacements of the cantilever for different cases (6 - 10)

\section{CONCLUSION}

The effect of device width of a piezoelectric cantilever on the displacement pattern is presented in this paper. The length and thickness of the device is fixed to the values of $10 \mathrm{~mm}$ and $0.62 \mathrm{~mm}$. However, the width is varied from $1 \mathrm{~mm}$ to $10 \mathrm{~mm}$ sequentially. Displacement measurements for each case are presented. From the results, it is obvious that, this changed geometry caused the nonlinear displacement patterns. The largest displacement of 9.80E-28 mm is found with smallest cantilever width of $1 \mathrm{~mm}$. However, the smallest displacement of 3.59E- $35 \mathrm{~mm}$ is found from $8 \mathrm{~mm}$ width. Interestingly, better displacements can be achieved with $7 \mathrm{~mm}$ and $10 \mathrm{~mm}$ widths compared to others. Among other width measurements, 7.85E-30 $\mathrm{mm}$ displacement is found with $5 \mathrm{~mm}$. For most cases, larger applied voltage caused higher displacements. However, in 3 cases lower voltages offer higher displacements. Hence, it is to conclude that, from this study, we found that, usually smaller width produces larger displacement. However, length and width ration cannot be justified accordingly as $7 \mathrm{~mm}$ and $10 \mathrm{~mm}$ widths measure better than rest of the width measurement.

In this paper, simulation measurement of the cantilever width is presented. The testing of the proposed cantilever in true environment is our next research agenda.

\section{ACKNOWLEDGEMENTS}

This work is partly supported by the Research Management and Innovation Centre of Universiti Malaysia Perlis, under fundamental research grant scheme (FRGS 9001-00569), Government of Malaysia.

\section{REFERENCES}

[1] M. E. Motamedi, MOEMS: micro-opto-electro-mechanical systems, SPIE Press,vol. 126, 2005.

[2] S. Nabavi, and L. Zhang. "MEMS piezoelectric energy harvester design and optimization based on Genetic Algorithm." In International Ultrasonics Symposium (IUS), IEEE, pp. 1-4, 2016.

[3] T. Tan, Z. Yan, H. Lei, and W. Sun. "Geometric nonlinear distributed parameter model for cantilever-beam piezoelectric energy harvesters and structural dimension analysis for galloping mode." Journal of Intelligent Material Systems and Structures, vol. 28, no. 20, pp. 3066-3078, 2017. 
[4] X. Li, W. Y. Shih, I. A. Aksay, \& W. H. Shih, "Electromechanical Behavior of PZT-Brass Unimorphs", Journal of the American Ceramic Society, vol. 82, no. 7, pp. 1733-1740, 1999.

[5] M. R. Awal, M. Jusoh, T. Sabapathy, M. R. Kamarudin, R. A. Rahim, \& M. F. A. Malek, "Power harvesting using dual transformations of piezoelectricity and magnetism: A review", 12th IEEE Student Conference on Research and Development (SCOReD), IEEE, pp. 527-532, 2015.

[6] U. Rabe, and W. Arnold. "Acoustic microscopy by atomic force microscopy." Applied Physics Letters, vol 64, no. 12, pp. 1493-1495, 1994.

[7] M. R. Awal, M. Jusoh, T. Sabapathy, M. R. Kamarudin, H. A. Rahim, \& M. F. A. Malek, "Analysis of a hybrid wireless power harvester for low power applications", In 10th European Conference on Antennas and Propagation $(E u C A P)$, Davos, Switzerland, pp. 1-5, 2016.

[8] M. R. Awal, M. Jusoh, T. Sabapathy, M. R. Kamarudin, \& R. A. Rahim, "State-of-the-Art Developments of Acoustic Energy Transfer", International Journal of Antennas and Propagation, pp. 1-14, 2016.

[9] A. G. Krause, M. Winger, T.D. Blasius, Q. Lin, O. Painter, "A microchip optomechanical accelerometer", Nature Photonics, vol. 6, pp. 768-772, 2012.

[10] W. C. Tang, T-CH Nguyen, and R. T. Howe, "Laterally driven polysilicon resonant microstructures", Sensors and Actuators, vol. 20, pp. 25-32, 1989.

[11] K. F. Wang, and B. L. Wang. "Energy gathering performance of micro/nanoscale circular energy harvesters based on flexoelectric effect." Energy, vol. 149, pp. 597-606, 2018.

[12] Q. Deng, and S. Shen. "The flexodynamic effect on nanoscale flexoelectric energy harvesting: a computational approach." Smart Materials and Structures, vol 27, no. 10, pp. 105001(1-15), 2018.

[13] M. M. Jazi, M. Ghayour, S. Ziaei-Rad, and E. M. Miandoab. "Effect of size on the dynamic behaviors of atomic force microscopes." Microsystem Technologies 24, no. 4, pp. 1755-1765, 2018.

[14] M. TK Hou, and R. Chen. "Effect of width on the stress-induced bending of micromachined bilayer cantilevers." Journal of Micromechanics and Microengineering, vol. 13, no. 1, pp 141, 2002.

[15] R. G. Ballas, "Piezoelectric multilayer beam bending actuators: static and dynamic behavior and aspects of sensor integration", Springer Science \& Business Media, 2007.

[16] E. Finot, A. Passian, and T. Thundat. "Measurement of mechanical properties of cantilever shaped materials." Sensors, vol 8, no.5, pp 3497-3541, 2008.

\section{BIOGRAPHIES OF AUTHORS}

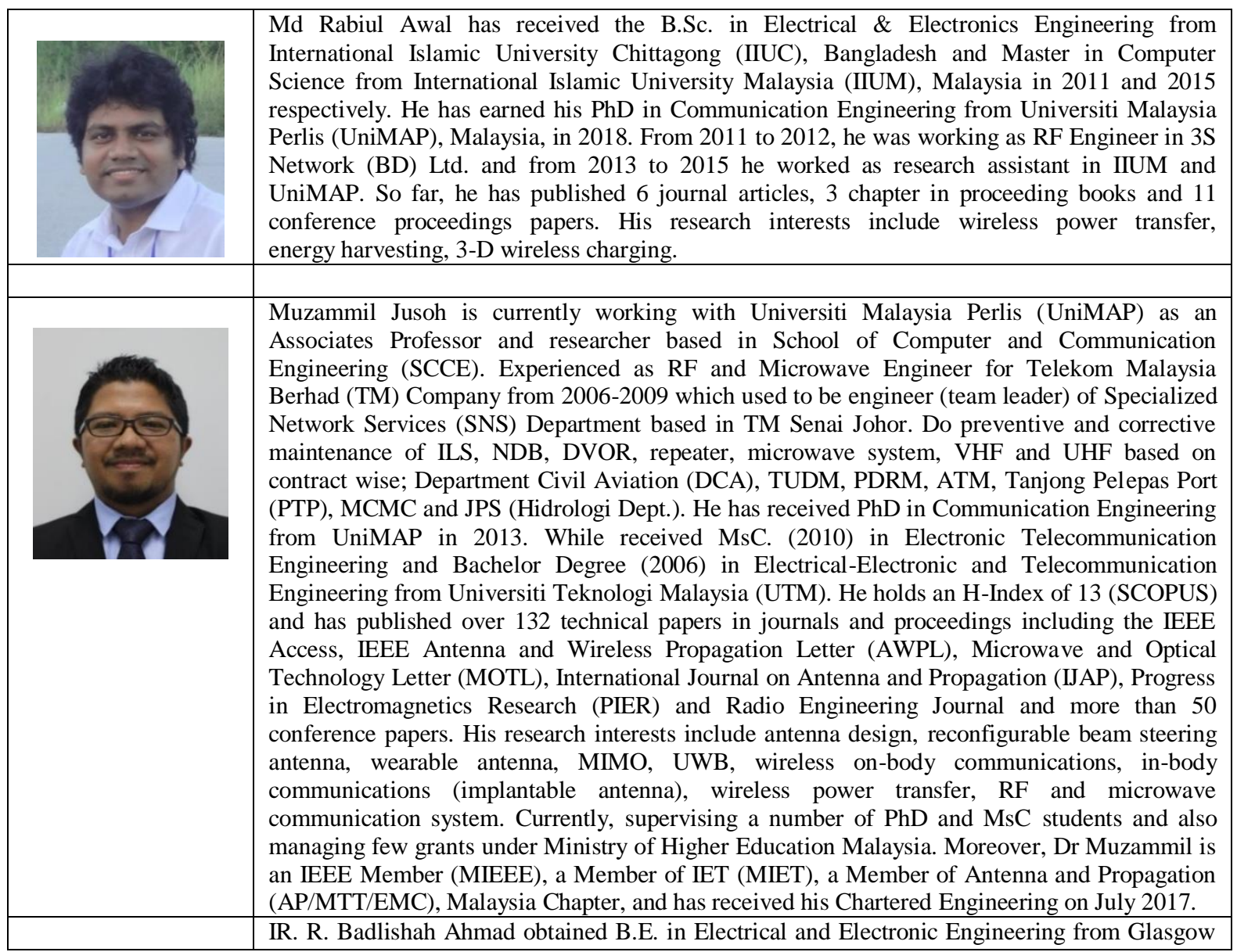




University in 1994. He obtained his M.Sc. and Ph.D. in 1995 and 2000 respectively from
University of Strathclyde, UK. His research interests are on computer and telecommunication
network modeling using discrete event simulators, optical networking and coding,
and embedded system based on GNU/Linux for vision. He has five (5) years teaching
experience in University Sains Malaysia. Since 2004 until 15 March 2017, he was working with
University Malaysia Perlis (UniMAP) as Dean at School of Computer and Communication
Engineering. Currently as the Deputy Vice Chancellor (Research and Innovation), Universiti
Sultan Zainal Abidin (UniSZA).

